\title{
Research on the Necessity of Local Agricultural Universities' Transformation to the Applied University
}

\author{
Shuxia Qian \\ Jilin Agricultural University \\ Changchun, China
}

\author{
Xiaoming Zhang \\ Jilin Agricultural University \\ Changchun, China
}

\begin{abstract}
The transformation of higher education is the inevitable trend for universities to adapt to the social and economic development. Therefore, it is necessary for local agricultural universities to transform the objective of talent training to the applied and provide the applied technical personnel for the rapid development of local agricultural economy. This paper analyzes the problems and states the necessity in the transformation of local agricultural universities.
\end{abstract}

Keywords-agricultural university; applied; transformation; necessity

\section{INTRODUCTION}

With the development of social economy in our country, the higher education becomes increasingly diversified. In the society of knowledge economy, the economic attribute of higher education receives the unprecedented attention. Some experts think the essential attribute of higher education is the applicability. It is further manifested in the era of knowledge industrialization. Universities will greet the era when the use value of knowledge is changed into value, which will have epoch-making significance. In the knowledge society, we should consider the kind of application instead of choosing between the applied and the non-applied in the higher education. The higher education only has two ways in the knowledge society, namely application and disappearance. [1] Therefore, the Ministry of Finance, the Propaganda Department of the Central Committee of the CPC and the Ministry of Education issued the Opinions on Guiding the Transformation of Some Local Undergraduate Colleges to the Applied Colleges in 2015. Afterwards, many provinces carry out the pilot work of transformation to the applied colleges.

Because of the local and regional characteristics, local agricultural universities should serve the local economy. The objective of talent training should meet the development of local economy, so it is necessary for the transformation of local agricultural universities to the applied. After the transformation, they should train the agricultural applied technical personnel to help the rapid development of local agricultural economy.

\section{PROBLEMS IN THE TRANSFORMATION OF LOCAL AGRICULTURAL UNIVERSITIES}

The higher education of our country has developed rapidly since the reform and opening-up. Local agricultural universities also get significant development. Some become stronger continuously in scientific research and training of students, gradually developing into comprehensive university and research-oriented universities. The objective of talent training is to train the compound and research-based senior specialized personnel. The transformation of general undergraduate colleges to the applied will bring many challenges and problems for the local agricultural universities to face and solve.

\section{A. Lack Clear and Scientific Development Idea}

In recent years, the research-oriented university, comprehensive university and first-class university are popular so that some local undergraduate colleges neglect the local and regional characteristics, lack the idea of serving the local economy and abandon the idea of running the applied colleges. They aim at running the research-oriented university, firstclass or domestic advanced universities, breaking away from the school-running essence of local universities. [2] So do the local agricultural universities. Therefore, local agricultural universities should timely change the idea and insist on the idea of applied talent training, improving the teaching quality and characteristics, changing the objective of talent training into the applied according to the requirements of national and regional economic and social development, so as to train applied talents for the development of regional economy.

\section{B. The Implementation of Policies Is Inadequate and the Fund Input Is Insufficient}

In the Opinions on Guiding the Transformation of Some Local Undergraduate Colleges to the Applied Colleges, the Ministry of Education states that enlarge the autonomous right of experimental colleges of transformation in financial management, increase the financial support for the pilot reform and improve related fiscal policies, giving preferential policy for the pilot reform, but in real work, it is not implemented timely in the transformation of universities and the fund support doesn't carry out. Therefore, governments at all levels 
shall adjust the structure of higher education, promote the transformation of higher education and further increase the financial budget for the applied undergraduate colleges, increasing the proportion of applied universities in the development of the whole higher education, bridging the gap of input between the affiliated universities and the local universities, encouraging the cooperation in running schools between the applied undergraduate colleges and enterprises, guiding and supporting universities to establish the school board and board of governors, so as to improve the overall school-running level.

\section{The Training Objectives Are Ambiguous, the Contradiction between Supply and Demand Increases}

With the rapid development of economy and higher education in our country, new pattern appears in the supply and demand of graduates of higher education. The objective of talent training in undergraduate colleges changes from the cultivation of senior specialized personnel to the cultivation of professional personnel at all levels and skill-oriented workers. The graduation whereabouts of most graduates change from government departments and public institutions and first-tier or second-tier cities to the enterprises and medium and smallsized cities and towns. However, at present, the objective of talent training of most local undergraduate universities is to train senior and mid-level professional personnel, and graduates go to government departments and public institutions, first-tier or second-tier cities, resulting in the increase of contradiction between supply and demand. Therefore, local undergraduate colleges should adapt to the significant changes happened in the supply and demand of graduates in the talent market and further promote the transformation development, changing the training objective from the cultivation of senior professional personnel to the cultivation of middle and junior professional talents and highskilled workers, changing the employment idea of college students, recognizing the employment tendency and aiming the employment direction at the blue-collar job and medium and small-sized cities and towns. [3]

\section{THE NECESSITY OF TRANSFORMATION OF AGRICULTURAL UNIVERSITIES}

In recent years, with the soaring development of higher education, the development idea and direction of universities change from the extension development aiming at the scale expansion and rank promotion to the connotative development with quality and benefit as the core. In the transformation from the quantity and scale to the quality and benefit, universities must solve problems about how to strengthen students' cultural literacy and graduates' competitive power through structure optimization and quality improvement and how to train more and better applied entrepreneurial and innovative talents.

The transformation of higher education is carried out early in powerful nations of education like America, Japan and Germany. The community colleges in America become the main structure of higher education to train the applied talents; short-term college, junior college and special training school in Japan are the cradles to train applied talents; in 1968, the German government decided to establish higher professional colleges to train applied talents. In 1998, the higher professional colleges began to provide education at the level of master and changed the name into "the universities of applied science". The universities of applied science play an important role in the higher education system of Germany. In our country, for over thirty years of the reform and opening-up, especially after entering the new century, the higher education develops rapidly, and the scale of it also increases sharply, but it excessively emphasizes the training of academic talents and neglects the training of applied talents, resulting in the lack of technical talents, influencing the economic development of our country. [4]

\section{A. The Transformation of Agricultural Universities Helps the Development of Modern Agricultural Science and Technology}

The twenty-first century is the era of high technology. The agricultural production of our country also enters the era of scientific and technological development. The forms of agricultural production change greatly. New science and technology has entered all links of agricultural production. The agricultural development has more and more requirements for new technology and increasingly depends on the higher agricultural education. The transformation of agricultural universities strengthen the cooperation between universities and enterprises, realizing the combination and promoting the unification of "industry, university, research and application", conducive to the transformation of achievements of scientific research, the improvement of scientific research level and the collection of scientific research funds in universities. The integration process of "industry, university, research and application" realizes the extensive promotion and application of new science and technology in agricultural production and helps the realization of agricultural modernization. Meanwhile, the transformation of agricultural universities also improves the teaching methods of agricultural universities, combines the theoretical knowledge with the practice and trains students' operational ability, training talents according to the requirements of local areas and enterprises, so as to highlight the ability of universities in supporting the development of local economy.

\section{B. The Transformation of Local Agricultural Universities Provides Vitality for the Development of School}

After the economic development of our country enters the new normal, the development of higher education also enters the new normal. Drastic changes happen in the macro control of enrollment scale of universities and the supply and demand situation on the talent market, restricting the development of some local universities and making them lose vitality. The vitality of university refers to the ability of university in independent development. The vitality of university lies in the sharp perception of social changes. It is necessary for universities to position accurately, adjust the direction according to social demands and continuously improve the degree of social recognition and stand out in the increasingly fierce competition. At present, the transformation of higher education brings vitality and opportunity for local agricultural universities and the development of school. Therefore, local 
agricultural universities should base on their advantages and characteristics, define the positioning and service direction and keep up with the local economic development, serving the local economy. Besides, they should change the objective of talent training into the applied and adopt good points and avoid shortcomings, training talents and high quality labors according to the requirements of local economic development.

3) The Transformation of Agricultural Universities Is the Requirement of Local Economic Development

Nowadays, the bilateral interaction of higher education and economy has become an inevitable trend. The economic attribute of higher education is the release and presentation of its industry attribute. The transformation of agricultural universities serves the local economic construction and development, selects "talents" for it and designs the scheme, training talents and high quality labors for the requirement of local economy and quickening the pace of integrating in the local economic development. Furthermore, the transformation of agricultural universities can establish better cooperative relationship with the local areas, connecting the universities with the local economic development, the talent training for enterprises with the requirement of technological innovation and forming the interactive development of universities and regional economic society. It promotes the transformation and upgrading of competitive industries with regional characteristics, the social construction and the basic public service, and quickens the integrative development of talent training, science and technology service and technological innovation.

\section{4) The Transformation of Agricultural Universities Makes the Innovation and Entrepreneurship Education Become Possible}

In 2015, in the implementation opinions on deepening the reform of innovation and entrepreneurship education in universities, the State Council states the deepening of reform of innovation and entrepreneurship education in universities is the crying need of the country to implement the innovationdriven development strategy and promote the economic effectiveness, as well as an important measure to promote the comprehensive reform of higher education and the entrepreneurship and employment of higher quality. The purpose of innovation and entrepreneurship education is to train students' ability, innovative spirit and consciousness of entrepreneurship. The ability training cannot do without the applied skills. The training of applied talents makes it possible for the innovation and entrepreneurship education. [5] The transformation of agricultural universities can integrate the innovation and entrepreneurship education in the whole process of talent training, organically combining the professional education with the entrepreneurship education, so as to improve the application-driven innovative ability.

5) The Transformation of Agricultural Universities Provides Talents for the Modern Agriculture

With the economic development of our country, a large amount of farmers swarm into cities and become peasantworkers or urban residents. The rural land has been transferred to a few farmers focusing on the agricultural production, making the agricultural production in our country lean to the intensive production. The agriculture about "who will do farm work in the future" must take the road of development with moderate scale. The operation type of single household impedes the promotion and application of new technology, failing to guarantee the quality of agricultural products. The intensive agricultural production needs a large number of new type farmers with education background and technology, adept in production and management. The senior applied technical talents trained by agricultural universities after transformation have the characteristics of new type farmers. They have profound theoretical basis and technology and strong practical ability. The agricultural universities after transformation will become the base of further education for the front-line technical talents of agricultural production depended by local governments, industries and enterprises, providing technical and talent support for the agricultural technical progress, the reform of agricultural industry and the development of emerging industries in rural areas.

\section{CONCLUSION}

To sum up, the transformation of higher education provides opportunities for the development of local agricultural universities. Local agricultural universities shall fully realize the importance of the transformation, free their mind, change and innovate in the ideas. Besides, they should keep pace with the economic development, quicken the transformation development and train applied talents with strong theoretical basis and practical ability, so as to meet the demands of local economic development for applied talents.

\section{REFERENCES}

[1] Wang Liping. Theory and Practice on the Transformation of Chinese Higher Education in the Era of Knowledge Economy [J], Journal of Taiyuan University, 2013 (12): 101-104, 116

[2] Zhang Yan, Xin Jingjing. Analysis on the Value Orientation of Education in the Period of Higher Education Transformation in Our Country [J], Journal of Social Sciences of Jiamusi University, 2015(2): 166-167, 179

[3] Yang Shengwen. The Supply and Demand Situation of Graduates Needs the Transformation of Higher Education-Dialogue to Hu Ruiwen, the Committee Member of National Education Advisory Committee [J], Occupation, 2013 (8): 28-31

[4] Wang Zhongkuan, Zhang Yang. The Transformation Development of Higher Education: Based on the Perspective of International Comparison [J], Journal of Dalian Education University, 2015 (6): 4446

[5] Yang Dongming. Barrier Breakthrough and Collaborative Innovation: The Road for the Transformation and Upgrading of Applied Higher Education [J], Vocational and Technical Education, 2013 (2): 44-47. 